\title{
NMR Spectroscopy Database and Searching System
}

Haw-Lih Su$^{1}$, Huei-Wen Winsome Teng ${ }^{2,3}$, Jeff Cheng-Lung Lee ${ }^{4}$, Mohammed Shkoor ${ }^{5}$, Mohammad Ibrahim Ahmad Ibrahim ${ }^{1}$, Mohammed Hussain S A Alsafran ${ }^{1,6}$ and Saeed H. Al-Meer ${ }^{1,5}$

${ }^{1}$ Central Laboratories Unit, Qatar University, Doha, Qatar

2 Department of Information Management and Finance, National Chiao Tung University, Hsinchu, Taiwan

${ }^{3}$ Institute of Statistics, National Chiao Tung University, Hsinchu, Taiwan

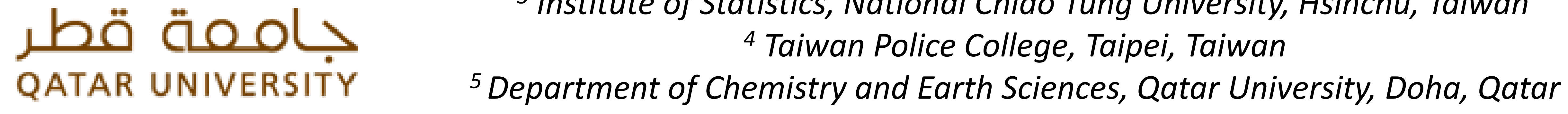

Faculty and PostDoc $\quad{ }^{6}$ Department of Biological and Environmental Sciences, Qatar University, Doha, Qatar

hsu@qu.edu.qa

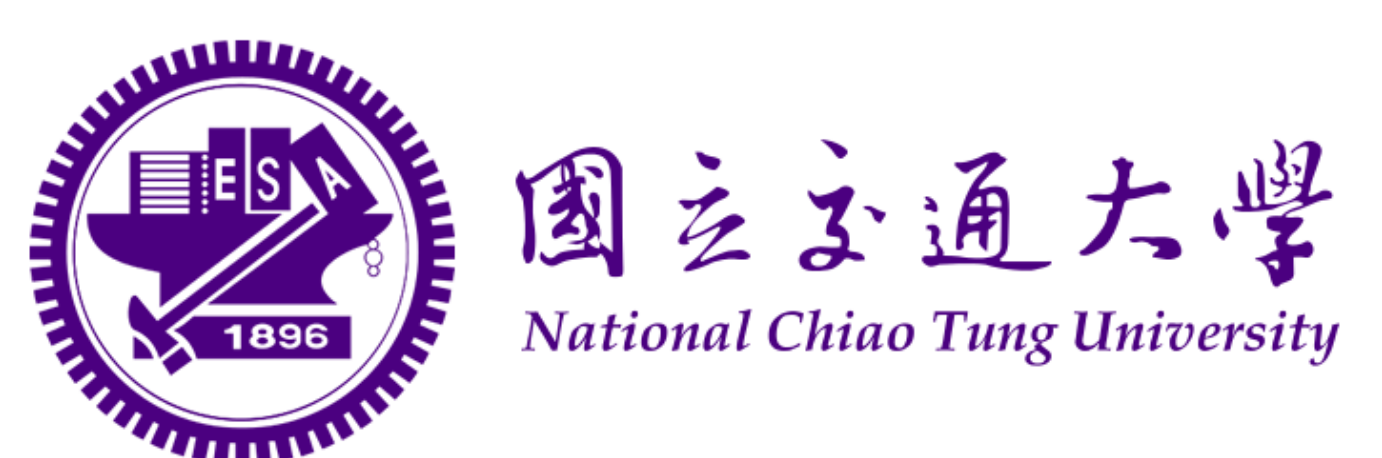

中華民國

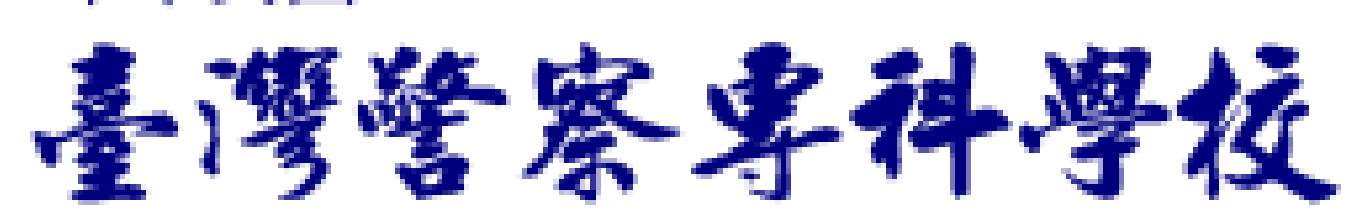

Taiwan police college

\section{Abstract}

NMR spectroscopy is the most important analytical technology for organic compounds and plays the key role for the chemical characterizations and identifications in chemistry, pharmacy, materials science, environments, biology, and many related fields. In most cases, a NMR spectrum is compared with the known spectra to check if the sample contains a known chemical or is a new product. However, the current comparison process relayed on human beings and waste a lot of time and efforts. A new database and searching system is thus in need.

\section{Typical Presentation Methods for a NMR Spectrum}

\section{A. Graphic Presentation: Good for human reading}
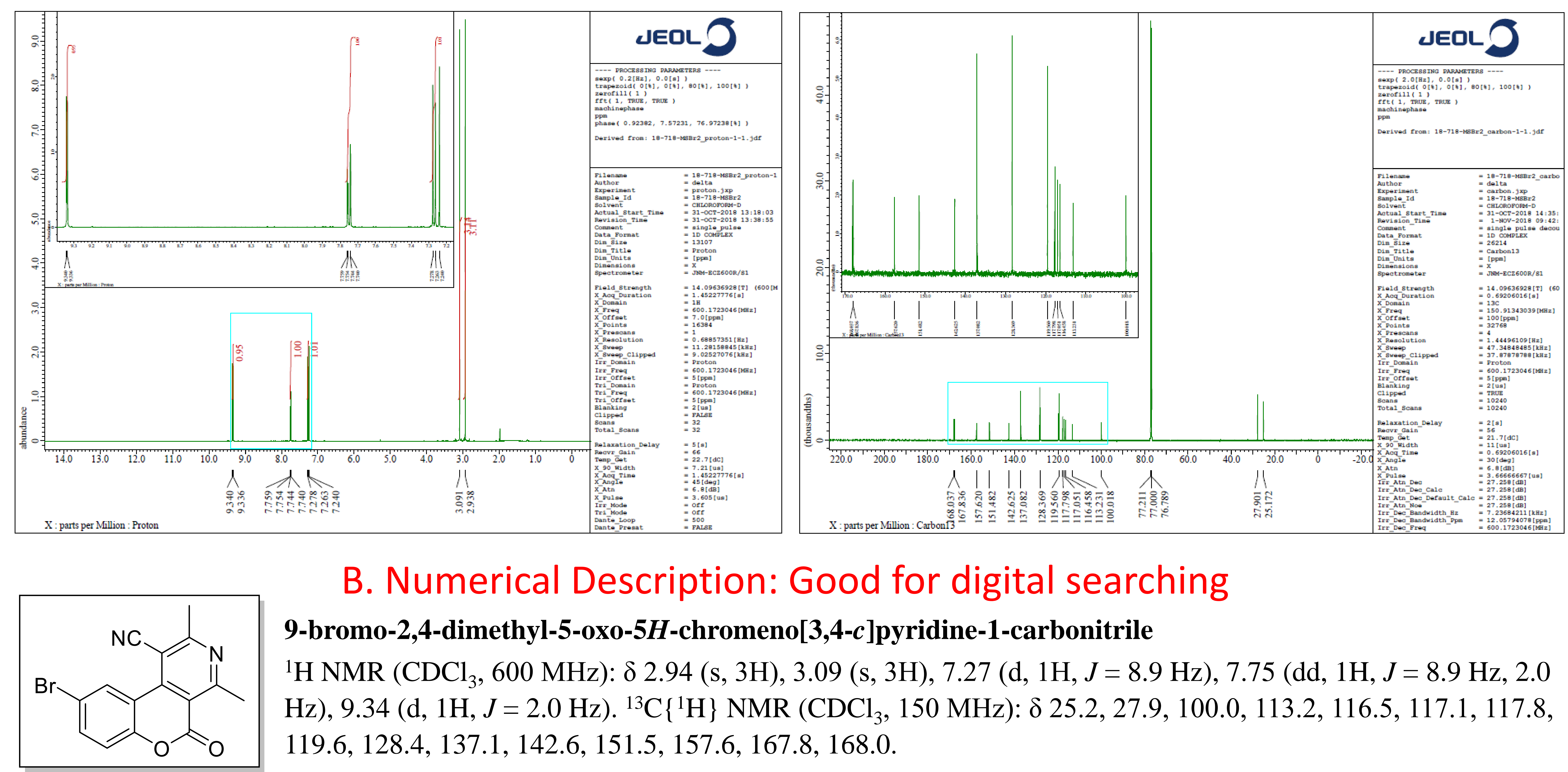

B. Numerical Description: Good for digital searching

9-bromo-2,4-dimethyl-5-oxo-5H-chromeno[3,4-c]pyridine-1-carbonitrile

${ }^{1} \mathrm{H}$ NMR $\left(\mathrm{CDCl}_{3}, 600 \mathrm{MHz}\right): \delta 2.94(\mathrm{~s}, 3 \mathrm{H}), 3.09(\mathrm{~s}, 3 \mathrm{H}), 7.27(\mathrm{~d}, 1 \mathrm{H}, J=8.9 \mathrm{~Hz}), 7.75(\mathrm{dd}, 1 \mathrm{H}, J=8.9 \mathrm{~Hz}, 2.0$

$\mathrm{Hz}), 9.34(\mathrm{~d}, 1 \mathrm{H}, J=2.0 \mathrm{~Hz}) .{ }^{13} \mathrm{C}\left\{{ }^{1} \mathrm{H}\right\} \mathrm{NMR}\left(\mathrm{CDCl}_{3}, 150 \mathrm{MHz}\right): \delta 25.2,27.9,100.0,113.2,116.5,117.1,117.8$,

$119.6,128.4,137.1,142.6,151.5,157.6,167.8,168.0$.

\section{Current Databases and Literature}

- Databases: Mostly in graphic; some in both. Only Searching by names and formula. Contains common chemicals only.

Literatures: Mostly in numerical; some has graphics in supporting information.

Researchers need to search and compare by themselves. No convenient or quick searching methods.

\section{Database Facilitated Screening and Chemical Identification Process}

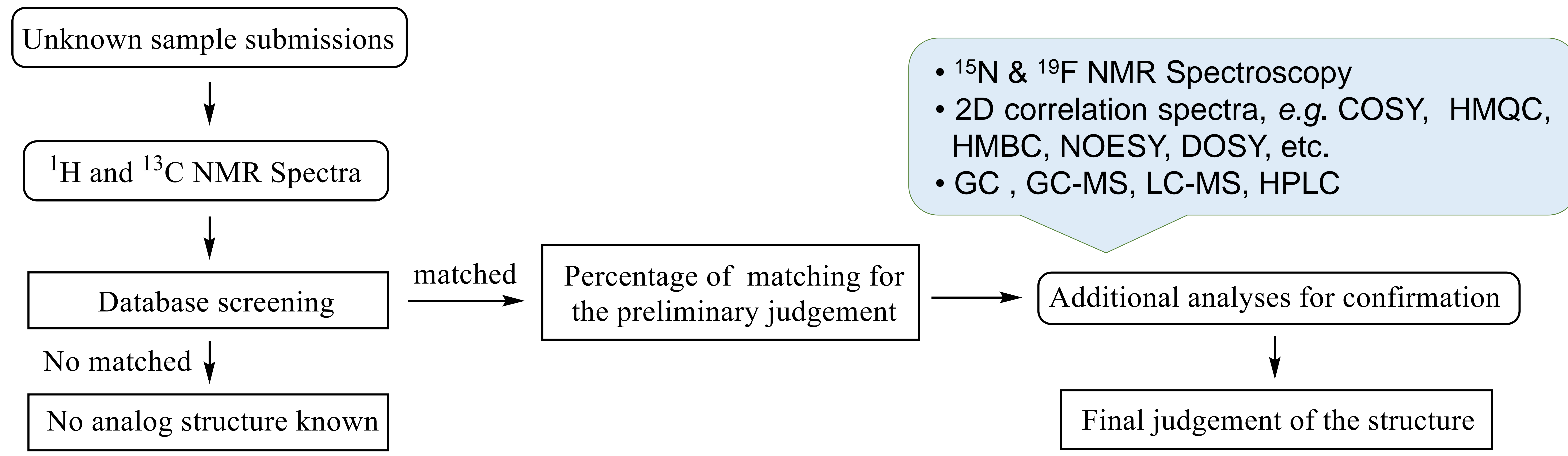

